[Hall, C. (1993). Developments in Academic Audit in New Zealand Universities. New Zealand Annual Review of Education, 2, 263-284]

\section{Developments in Academic Audit in New Zealand Universities}

\section{CEDRIC HALL}

$\mathrm{A}$ s in other countries, education at the tertiary level in New Zealand has undergone major organisational, structural and funding changes in recent years. At the same time tertiary institutions have been placed under increasing pressure both to make more efficient use of their resources and to ensure that they provide a "quality" education to their communities. This pressure comes at a time in New Zealand when student numbers, but not resources, have increased substantially.

This paper focuses on developments by New Zealand universities to monitor jointly the quality of their academic activities. During 1992, the New Zealand Vice-Chancellors' Committee (NZVCC), with assistance from the University Teaching Development Centre (UTDC) of Victoria University, organised three workshops/seminars on the theme of quality assurance in New Zealand universities. This paper provides a synopsis of the discussions and outcomes of the three meetings, including coverage of the pressures for change, the issues that were debated, and the self-examination required of universities as they prepare for the first round of "academic audit". A summary is also given of developments in British universities because of the strong British influence on New Zealand developments and the similarity between many of the issues confronted in the United Kingdom and those being encountered in New Zealand.

\section{British Developments in Academic (Quality) Audit}

The first seminar was held in January 1992 to coincide with the visit to New Zealand of Peter Williams, the Director of the Academic Audit Unit (AAU) in Britain. This Unit was set up by the Committee of ViceChancellors and Principals of the United Kingdom (CVCP) in 1990 to monitor and comment on: the structures and mechanisms by which the institutions [i.e., universities] themselves assure the quality of the educational programmes they offer, in fulfilment of their formal responsibility to set and maintain their own academic standards. (Williams, 1991, p. 3)

The factors leading to the development of the AAU are outlined by Williams (1991) and include the political pressures associated with the "accountability" and "value-for-money" philosophy introduced by the Conservative Government in the 1980s. Prior to this period little formal attention was given to the need for universities to check the quality of their programmes - the general assumption being that the existence of the external examining system, with the role of ensuring comparability of standards within disciplinary boundaries, provided the necessary checks. According to Williams:

Beyond that [i.e., the external examiner system] a high degree of selfconfidence (if not complacency) within the universities, legitimised in their eyes by the selective student entry system and impressive graduate success, milita ted against any significant internal or external scrutiny of the quality of the teaching function. Difficult questions were dismissed by reference to academic freedom and autonomy, and by an insistence that none but the expert practitioner was in a position to pass judgment on academic matters. (Williams, 1991, p. 1)

As a response to the various pressures on them, the universities through the CVCP undertook a series of efficiency studies which, although supporting many of the current practices in universities, advocated the development of a more streamlined and directive managerial approach to administration (Jarrat, 1985). The CVCP also set up an Academic Standards Group which established three formal codes of practice and provided other guidance to assist universities in their own selfexamination (Reynolds, 1986). One of the fears of the universities was that if they did not take action to monitor their own quality, mechanisms and procedures would be imposed from without. This threat was given emphasis by the Educational Reform Act of 1988 which established the Universities Funding Council (UFC); this body made it clear that it would take action if the universities did not themselves. The Academic Standards Group subsequently recommended the creation of the AAU to be owned by the universities under the auspices of the CVCP. The CVCP looked at various models of operation for the Unit, 
including the inspectorial approach of Her Majesty's Inspectorate (HMI) and the validation and accreditation roles of the Council for National Academic Awards (CNAA), before finally settling for a system of academic audit more akin to financial audit models.

The principal focus of the AAU has been on auditing universities' mechanisms for assuring quality in the design of courses and degree programmes, the monitoring of teaching and assessment standards, the provision of staff development programmes and staff appraisal schemes, and the extent to which the views of external examiners, students and external bodies are taken account of in reports and reviews of courses (see Williams, 1991, pp. 4-5). The research productivity of universities has not been a focus of attention of the Unit, this being assessed through research selectivity exercises under the control of the UFC.

Once established, the AAU appointed an initial team of 14 auditors drawn widely from nominations supplied by universities. A draft methodology for conducting audits was trialled in five universities and subsequently modified in minor details (e.g., to ensure greater standardisation in the style and format of reports). The revised methodology has now become the standard approach. In brief, institutions are given several months notice of an audit visit, and are required to supply documentation about goals, programmes, quality systems, committees, faculty structure, and so on. Each audit is undertaken by a panel of three auditors supported by an audit secretary. The audit panel scrutinises the documentation and develops a plan for the visit which includes meetings with staff of all levels and a range of undergraduate and postgraduate students. During the visit, the focus may be refined to pick up on particular points that arise or strike the attention of the panel. Visits last three days and typically involve meetings with around 150 people. Following the visit, each panel is responsible for producing a report which is sent to institutions to correct factual errors but not to change the views or recommendations of the panel. Institutions are expected to make available their final reports after a period of ten weeks; this period gives institutions the opportunity to circulate the report internally and consider their own response.

A recent paper by Gordon (1992) indicates that institutions find the visit a demanding task and that pre-audit reactions: range from hostility or annoyance to trepidation or uncertainty but those who meet with the audit team tend to become intrigued by the exchanges and respond positively, or fairly positively. (Gordon,1992, p. 4)

Gordon also concludes that audit reports:

are generally perceived by institutions as fair, balanced and perceptive documents. (ibid, p.4)

A similarly positive view on the whole audit process is provided by Williams (1992) in the first Annual Report of the Director 1990/1991. He notes that although different approaches to academic audit are followed in universities, all invest a considerable amount of time and effort in dealing with the questions raised by the audit process. He points out that the effort is not simply a matter of window dressing for the benefit of the visit, although it is clear that such visits have a "galvanising" effect in forcing institutions to confront difficult problems. Williams also notes that even though academic audit is a recent development:

its value as an aid to the enhancement of quality (both of teaching and learning) is increasingly being acknowledged. It is less common to hear the opinion (quite frequent, even a year ago) that the whole business is a waste of precious time and scarce resources, or an affront to the principles of academic freedom. (Williams, 1992, p. 20)

It should be noted that in 1992 the AAU was relocated under the structure of the new Higher Education Quality Council (HEQC) and renamed Quality Audit. The HEQC will serve all universities under the new post-binary system of higher education in Britain, effectively doubling the number of universities to be visited. A fourth tranche of auditors has now been recruited. The first cycle of visits to the "old" universities will be completed by the end of 1993 indicating, as Gordon points out, a rate of growth consistent with general acceptance of the role of audit in quality assurance.

\section{The First NZVCC Seminar on Quality Assurance (January 1992)}

The first NZVCC seminar provided the opportunity for New Zealand academics to hear first-hand the experiences of the British system and to consider the direction or strategy that New Zealand universities might follow. The seminar was attended by 17 representatives from six of the seven universities. During the morning session Peter Williams 
outlined developments in the British system and answered questions from participants. In the afternoon session, David Hamer (Assistant Vice-Chancellor, Victoria University) provided background information on the New Zealand scene - the quality assurance procedures already in place by most universities and the pressures on New Zealand universities to examine their own procedures more closely - and Chris Dearden (Deputy Vice-Chancellor, Victoria University) outlined the obligations of universities under the Public Finance Act and the Education Act to provide a statement of objectives and a service performance statement in relation to these objectives. This was followed by discussion of two questions: Should New Zealand universities seek to develop a quality audit mechanism? If so, what was the next step?

In relation to pressures on New Zealand universities to take action, David Hamer identified overseas developments, political-economic pressures within New Zealand, the creation of the New Zealand Qualifications Authority (NZQA), growing competition between universities for students (e.g., through distance education), and internal pressures from students and staff for improvements in teaching and resources, as all being associated with the need for universities to examine their quality systems (reported in Hall, 1992a). Hamer identified, in particular, the "user-pays" philosophy of the Government as giving weight to the demands of the universities' clients (students, parents, employers, etc.) for better quality teaching and education. He also drew attention to the relationship of the NZQA to universities as identified by the Education Amendment Act 1990; this Act assigns an audit role to the NZQA in relation to the NZVCC's application of course approval and accreditation criteria within the universities. (It should be noted that although the operational details of this relationship have yet to be defined, it is now clear that the intrusiveness - or lack thereof - of the NZQA will be influenced by the approach and thoroughness of the audit activities undertaken by the universities themselves.)

Hamer also drew attention to a number of quality control and assurance mechanisms already in place which, although well recognised in universities, were little known by outside groups. The mechanisms listed included the use of external examiners for assessing theses and honours examinations, the work of the NZVCC Committee on University Academic Programmes (CUAP) in approving new programmes and qualifications, and the use of external reviews of departments to ensure that New Zealand programmes and research are of international standard. Hamer also noted that universities employ a range of internal procedures for dealing with matters such as course approvals and changes, the monitoring of student workloads and assessment, the handling of student appeals and grievances, and the evaluation of teaching using feedback from students, colleagues and other sources. However, Hamer emphasised the need for universities to make more transparent their mechanisms for monitoring the quality of their activities, and to ensure that such systems are regularly reviewed to ensure that they remain appropriate for the task in a changing environment.

In relation to the requirement of universities to supply an annual service performance statement, Chris Dearden noted the following concerns (Dearden, 1992): that the performance statements provide accountability to the Government but give less useful information to other clients such as students, parents, and employers; that accountability is a two edged sword, and that while universities should be accountable for expenditure of public money, the Government should also be accountable for decisions which impact on the universities' ability to meet their objectives (e.g., the expectation of Government that universities will provide more places while only funding for a specified number of enrolments); that there is a temptation for Government and other bodies to demand more and more accountability from an already over-stretched university system where research time, in particular, is at a premium; and that while universities should be conscious of cost effectiveness in providing an education, the best value for money in the long run is not likely to come from providing the cheapest system of education.

Following the above presentations, participants broke into three groups to discuss whether New Zealand universities should develop a quality audit mechanism of their own. While all three groups supported the notion, concern was expressed that the size of New Zealand would make it difficult to establish a unit that would be accepted as providing independent evaluations; the seminar concluded that overseas auditors should be part of the process. There was also agreement that universities should take action before a system was imposed externally, and that the universities should drive the agenda for the development of a system. This was seen as being more likely to result in real benefits to the universities themselves. The discussion also pointed to the need for universities to document the quality systems already in place and to 
make public the nature and extent of their activities. Views were also expressed that universities would need to "beef up" their external examining systems, and that the agenda for the three year subject conferences (an inter-university forum organised on a subject basis) should include consideration of quality assurance and quality assessment issues (quality assessment is discussed later). Finally, the seminar provided strong support for the notion that the enhancement of quality, rather than the policing of its absence, should be the major focus of a quality audit system. This theme was reiterated in all three NZVCC seminars/workshops. The seminar concluded with a recommendation that a workshop, involving greater representation from each university, be held in May to develop a firm proposal on academic audit in New Zealand universities.

\section{The NZVCC Two-Day Workshop on Quality Audit (May 1992)}

In preparation for the May workshop, universities were surveyed for information on their policies and practices in a number of academic or academic-related areas (Hall, 1992b). The survey sought information on: the evaluation of teaching, including the use of student feedback; promotion and probationary procedures for academic staff; the existence and operation of appraisal schemes; academic staff development programmes and structures; the scope and operation of EEO policies; the implementation of charter obligations on biculturalism; the ongoing monitoring of individual courses in respect of their design, content, assessment, and student workloads; and the provision of learning support services for students. The results of this survey, along with information from an earlier survey on universities' policies/practices on assessment, external examining and departmental reviews (NZVCC, 1991), provided useful background information for supporting the discussion and activities of the workshop.

The May workshop was attended by 31 participants, including four representatives from each of the seven universities. The New Zealand polytechnic sector and the New Zealand Universities Students' Association were also represented, and Professor Ian Chubb, Director of the Higher Education Council of Australia, attended as an invited speaker. The workshop was convened by Professor Wilf Malcolm, Convener of CUAP and Vice-Chancellor of the University of Waikato.

In his opening address, Professor Malcolm reiterated the pressures upon universities for taking action and the need for such action to be under the control of the universities themselves in order to ensure most benefit to the system. This address was followed by a paper by Cedric Hall, which highlighted some of the quality questions relating to the design of individual courses and the provision of a teaching environment conducive to student learning. A brief explanation of the Massey University policy on quality assurance in teaching was then provided by Professors Graeme Fraser and Tom Prebble (Massey), and Ian Chubb concluded the first session with a description of Australian developments as being undertaken by the Higher Education Council. Each of these addresses/presentations is contained in a Workshop File along with reports of the proceedings and outcomes of the workshop (NZVCC, 1992a).

For the second session, participants were assigned to one of six groups, with each group being responsible for identifying the important quality issues that should be addressed in a particular area. A brief summary of each group's deliberations is provided. The following material draws heavily on a report provided by the writer (Hall, 1992c) and notes supplied by the six group facilitators.

\section{Group 1: Monitoring of qualifications and programmes}

In general, this group thought that the monitoring of new qualifications was much better done than the monitoring of existing programmes. However, the group questioned whether peer approval of new programmes was sufficiently objective. For example, does CUAP give enough attention to national interest?

In respect of the monitoring of existing programmes, the group raised the question as to whether CUAP might be asked to accredit institutions to continue as providers of existing programmes. The group pointed out that different quality control (QC) and quality assurance (QA) procedures exist in universities, and that once a programme is launched, a university should define its quality procedures so that the programme can be monitored.

There was agreement in the group that the audit function should be independent of existing QC and QA procedures (i.e., the audit should be external to what was being done internally in universities or through external reviews, external examiners, etc.), and that an external auditing body, if set up, should have access to reports of departmental reviews and information relating to the actions that have been taken on the review recommendations. 
In the plenary discussion of the group's report the point was made that an external audit would at least challenge universities to think about what they do, that is, it would encourage universities to undertake internal audits.

\section{Group 2: The interface between universities and their client communities}

This group focused on identifying questions (not answers) that QA procedures should be addressing in relation to the interface between universities and their client communities. The group felt that it was up to universities individually and collectively to answer these questions. The questions posed were: Who are the potential clients for the learning, research and scholarship opportunities that our universities provide? Who are our actual clients? Are all our potential clients aware that they have rights in respect of access, representation and consultation? Are obstacles to access, representation and consultation being identified and removed?

The group also raised questions (but again provided no answers) as to what information needed to be gathered to answer these questions, who should be asking these questions (insiders/outsiders), and the procedures to be used to ensure that QA and QC procedures were transparent to all interested groups.

The plenary discussion highlighted a possible conflict between clients' perceived needs (immediate job skills) and the traditional goals of university education (e.g., generic skills). Other points discussed included the provision of bridging courses, the need to reconsider entry requirements, and the need to involve our communities on equity issues. Consultation with different client groups was seen as a way of breaking down the mystique of universities.

\section{Group 3: Monitoring staff performance and development}

As a general point, this group saw the key value of an external audit mechanism as the self-evaluation it would promote within institutions. In respect of mechanisms for monitoring staff performance and development, the group argued that universities should have job descriptions, a system of mentoring (e.g., an annual meeting with a colleague for the purpose of annual forward planning and professional development), staff appraisal processes looking at each staff member's job description and contribution to the department's mission, and regular and systematic departmental reviews. Regular staff appraisal processes were seen as essential for giving recognition to good performance (e.g., through confirmation of appointment, promotion, study leave, research grants), for allocating resources (e.g., for conference leave, study leave, change of responsibilities, research grants), and for action to remedy unsatisfactory performance.

The group identified two issues: (i) the need for universities to have a probationary period with procedures for fostering staff development but also for improving control on the confirmation of permanent staff (procedures must have "teeth"); (ii) the need for greater care in the assessment of research/scholarship - too often a model suited to the sciences is imposed on other disciplines.

The plenary discussion covered the need for equitable workloads for new staff, the development of consistent probationary policies which give clear guidance to new staff, and the need for all staff to be appraised at least every three years so that senior staff who do not seek promotion do not escape the quality net. The plenary also drew attention to the need for clarification in the terminology covering staff development and appraisal.

\section{Group 4: Assessment, external examiners and external reviews}

This group focused on the QA processes that might be supported by an external audit mechanism. The group argued that audits should be based on some notion of best practice to be developed by the audit unit. The audit team should include non-New Zealand university personnel and might possibly buy into the Australian system depending on how audit develops there.

The group recommended the "beefing up" of the external examiner system for discipline based evaluation at the postgraduate level. Again the group saw the need for the development of a statement of best practice for assessing courses and programmes. The extension of the external examiner system to undergraduate programmes should also be considered if costs permit.

The plenary discussion questioned the notion of "best practice", pointing to the need to assess practices and procedures against stated goals. There was also debate about the role of the external examiner given the concerns raised by the CVCP Audit Unit about the British system (Williams, 1992). The need to distinguish between the content, teaching and assessment of post-graduate courses was stressed; realistically, external examiners could only focus on assessment 
standards and procedures because of the limited time-frame for getting papers to examiners and results returned. The notion of quality assessment was raised - external (e.g., departmental) reviews were seen as providing an assessment function.

\section{Group 5: Monitoring the quality of individual courses}

This group saw its focus as being on the monitoring of existing courses or units (not programmes). The group noted that it was much more common to find new courses and programmes being established than old ones being removed. They saw the university curriculum as being far too cluttered, often lacking "external coherence" (see below).

The group saw the need for quality systems to be planned into a programme and its courses, not just developed as an after-thought. Within universities, mechanisms for checking the quality of courses should be instituted at both the department and faculty levels.

The group saw the need for some form of course design model which promotes "internal" and "external coherence" but which does not constrain spontaneity and innovation in course design and delivery. ("Internal coherence" refers to the way the different components of a course - the goals, assessment requirements, content, and teaching methods - hang together; "external coherence" refers to the way a course relates to other courses in the same programme, that is, the extent to which the goals of a course are consistent with the broader programme goals (see Hall, 1992d)). The model would need to be able to cater for different kinds of courses or be able to be adapted for such variations. It should be noted that this emphasis on the development of a course design model reflected concern that universities might be pressured to follow the NZQA model for approving courses as suitable for the Framework. The point was made that universities should make explicit the particular approaches they follow and justify why these are appropriate for their needs.

The group also recommended that courses be periodically monitored in relation to the suitability of their course materials, student achievement of the learning outcomes, the quality of teaching, and the relevance and value of assignments. Feedback might be sought from students, colleagues, observers, and client groups.

The group also recommended the preparation of a course report which draws together the evaluative information and can be used as evidence for audit and other purposes. Decisions would need to be made about the format, content and frequency of course reports.

The plenary discussion focused principally on three main concerns: that course objectives provide an appropriate balance between the general (broader university) and the specific (narrower subject) goals; that audit procedures focus on identifying good practices as well as commenting on failures; that a requirement be introduced that universities report back to CUAP periodically on the quality of their programmes.

\section{Group 6: Monitoring of scholarship and research activities}

This group initially considered the question: what are universities good at? The group suggested that universities provide a research climate which is conducive to encouraging enquiry, to maintaining a breadth of view across a wide range of disciplines, and to allowing for creativity and new ventures.

The group then considered procedures for ensuring quality at the individual level. They saw the need to separate appraisal from development but also questioned whether individuals can be allowed a totally free rein in their research activities outside of departmental goals. Appraisal was seen as important for aiding staff to change direction and for restarting poor performers.

Simple research statistics (e.g., number of publications, value of research grants) were not seen as sufficient for judging the quality of an individual's research work. The group saw the use of peer review as important for judging the merit of promotion cases, study and conference leave applications, and research grant allocations.

The discussion then moved to consideration of ensuring quality at the collective level. The importance of an environment with a strong research ethos was re-emphasised as essential for encouraging enquiry and building a long term commitment to quality in research. The group saw as important the need for institutions and departments to encourage the development of generic research skills in both staff and students. They also suggested the importance of appointment procedures, a mentoring system, and departmental reviews for ensuring quality at the collective level of departments or other groupings.

The group also looked at the research/teaching nexus, with particular reference to research supervision and assessment. The group noted that the links between teaching and research were well made at the postgraduate level, and that well-established QC procedures exist 
for examining but not supervising graduate research. At the undergraduate level, the connection between research and teaching was not as obvious, nor was it clear whether a research ethos was seen as part of undergraduate programmes. The group felt that the links between teaching and research at this level needed much greater reinforcement.

The plenary discussion drew attention to the need for universities to include equipment and the resourcing of research in the audit process. The discussion also drew attention to the need for universities to take a broader view of research so as to give appropriate recognition to the kinds of scholarship evident in fields such as art, music and drama. Concern was also expressed as to whether New Zealand universities were losing their range of research expertise because of policies and pressures which are currently changing the face of tertiary education. Some attention was also given to the link between assessment procedures used at the undergraduate level and the encouragement of a research ethos in students. Concern was expressed that too much weight is given to assessment tasks which encourage reproduction of information rather than engaging students in their subject through project work and other in-depth activities.

\section{Plenary discussions and outcomes of the workshop}

Following the group presentations and discussion, participants debated the direction that universities should take in developing a QA mechanism over and above procedures currently in place within universities. The outcome of this debate was unanimous support for the establishment of a universities' academic audit unit. It should be acknowledged that the debate did not deliberate in detail the merits of alternative models, such as that developed in the Netherlands where subject experts assess the quality of individual programmes or disciplines across institutions (see Vroeijenstijn, 1991, and Kalkwijk, 1991). The general feeling of the workshop was that a mechanism was needed to look at each university as a total unit rather than separately audit or assess the individual programmes or subjects offered. A "global" approach was seen as complementing information obtained from departmental reviews, reports of external examiners, and other similar mechanisms, most of which operate at a subject/discipline level.

At this point, the workshop broke again into groups under the facilitation of CUAP members. Each group was asked to identify the important issues that they saw as underlying the establishment of an audit unit, and to make suggestions where possible. The key points to emerge from these discussions were:

Workshop report: That a report of the workshop should be prepared and circulated to universities for discussion and feedback. The report should invite universities to agree in principle to the creation of a joint audit unit similar to the AAU in the UK. The report should also contain suggestions as to the scope, structure, powers and operation of the unit.

Powers of universities and the unit: That universities should contribute collectively to the development of the unit, have autonomy to opt in, comment on their own audit reports for factual errors (but otherwise not amend them), and have jurisdiction for acting on the reports. The audit unit would have jurisdiction over the conduct of the audit and responsibility for producing reports. The reports should preserve confidentialities within the university. The universities would own the reports, which should be made public. Scope and focus of the unit: That the terms of reference for the unit should be based on those identified by the AAU in Britain (see later) but also include the universities' obligations to the principles of the Treaty of Waitangi (see next). The focus of the unit should include, like Britain, universities' mechanisms for assuring quality in the design of courses and degree programmes, the monitoring of teaching, learning and assessment, and the extent to which the views of students and external groups are sought and taken account of in review processes. In addition, the unit should focus on the research profile and output of universities, mechanisms for appointment of staff, access and selection of students, and the support services provided to students insofar as they contribute to the quality of the academic learning environment. (See CUAP, 1992.)

Treaty of Waitangi: That the unit should involve Maori participation and representation, and that the terms of reference of the work of the unit should include universities' charter obligations in respect of the principles of the Treaty of Waitangi.

Relationship with other agencies: That the relationship between the audit unit and other agencies (e.g., Government Audit Office and NZQA) be clarified. 
Accreditation: That the powers of accreditation should remain with CUAP, and be seen as a separate function from audit.

Costings: That careful costings of the unit should be made to ensure that they do not represent an unreasonable burden on the universities.

The workshop also considered whether the unit should be separate from the NZVCC and whether it should be housed in Wellington or elsewhere; no firm recommendations were made. Discussion on the representation of the unit included suggestions that the unit comprise 10-12 auditors from New Zealand universities and 3-4 from overseas, and that audit teams comprise 3-4 auditors. The workshop also recommended that the audit unit employ an executive officer. It was generally agreed that auditors would need training and that support from overseas might be needed for this. Lastly, the cycle for conducting audits was discussed, with views ranging from once every three years to once every five years.

\section{Reaction of Universities to the Report of the May Workshop}

Following the May workshop, a report was prepared by Professor Nicholas Tarling on behalf of CUAP (CUAP, 1992), circulated to workshop participants for comment, and then forwarded to universities. The report incorporated most of the points summarised above.

The reaction of universities was one of qualified support. The concerns expressed included: funding (that the costs of the unit be contained); the selection of auditors (that panel members be "neither 'cosy' about universities nor ignorant of them" (NZVCC, 1992b); the focus of the unit (to encourage excellence, not to police the lack of it); the demands of audit on staff time; the need to involve lay consultation and input in the audit process; the need to clarify the relationship of the audit unit to the NZQA; and the need for further debate on alternative models.

The last point reflects the concern from one university that insufficient consideration was given to alternative models, such as the Netherlands system, the place of total quality management (TQM) in university settings, and the role of quality assessment in evaluating the teaching performance of academic staff (see next). As mentioned earlier, the AAU model was not seen by the May workshop as a competitor for these other approaches but rather as a means of providing information to a university as a whole about its quality assurance mechanisms. In other words, should a university choose to adopt, for example, a TQM approach to ensuring quality, its systems would still be open to academic audit to see if they are appropriate, provide useful information and checks to the university, and maintain and/or enhance academic standards.

\section{The Third NZVCC Workshop/Seminar (August, 1992): Developments} In Quality Assessment in Britain

A third workshop/seminar was held at Victoria University in August to coincide with the visit to New Zealand of Professor George Gordon, Director of the Centre for Academic Practice at the University of Strathclyde. Professor Gordon was one of the first academics invited by the CVCP to be an auditor for its Unit. During the seminar, Professor Gordon outlined the present status of academic audit in Britain, including the relocation of the CVCP Unit within the framework of the Higher Education Quality Council. His presentation provided, in particular, useful information on the audit process from the perspective of both an auditor - the work involved, the procedures followed, and the reactions of universities - and a recipient of the audit process (Strathclyde having recently been audited). A report of this seminar is summarised in a NZVCC report (NZVCC, 1992c); it should be noted that Professor Gordon led seminars covering the same ground at Auckland University.

Professor Gordon also reported on the development of "quality assessment" provisions in Britain as an outcome of the 1991 White Paper on Higher Education. Under the new Higher Education funding structure, three regional Funding Councils have been established to replace the existing UFC and Polytechnics and Colleges Funding Council (PCFC). Each of the regional funding councils has been required to set up a quality assessment committee to assess the quality of teaching in higher education. The White Paper defines quality assessment as:

external review of and judgments about, the quality of teaching and

learning in institutions. (Higher Education: A New Framework, 1991, p. 24.)

As currently being developed and trialled, quality assessment represents a far more intrusive and inspectorial type of monitoring than that 
provided by academic audit. Academic audit leaves universities to check their own performance - the audit process focuses on whether suitable systems exist for doing this - but quality assessment involves visits by an external panel (at the moment comprising seven members) who make assessments of the quality of the teaching in a particular subject across universities. Initial reactions are that the system in its present form will be unaffordable because of the large number of different subject areas and universities to be inspected. It is sufficient to say here that the third NZVCC workshop recommended against the inclusion of an assessment function in the work of the proposed New Zealand audit unit. A recent report on British developments by John Jones (Director of the Higher Education Research Office, University of Auckland) concludes:

While the process of Quality or Academic Audit appears to be fulfilling a useful function, there is very serious doubt about the utility of Quality Assessment procedures as currently implemented. (Jones, 1992, p. 4)

\section{The focus of the proposed New Zealand Universities Academic \\ Audit Unit}

Following receipt of each university's submission on the report of the May workshop, a firm proposal for the creation of a New Zealand Universities Academic Audit Unit was sent to each institution (NZVCC, 1992d). Universities were asked to respond by 27 February, 1993.

The terms of reference and focus for the proposed unit are given in Figure 1 . The proposal follows closely the AAU model, but with some important differences to suit the New Zealand context. For example, the terms of reference include an item related to the universities' obligations to the principles of the Treaty of Waitangi, and the focus includes consideration of appointment procedures and research.

The proposal also suggests that the unit focus on the work of CUAP insofar as it relates to the terms of reference of the unit. CUAP, with its role of approving programmes and qualifications, is clearly a major component of the universities' mechanisms for quality assurance.

Other recommendations contained in the proposal include:

- that the unit be based in Wellington, in close proximity to the NZVCC, but not formally part of it;

- that the unit comprise a small secretariat (a full-time director and secretary), a pool of auditors, and an advisory board;
Figure 1 Proposal for a Universities Academic Audit Unit - Terms of Reference and Focus (from NZVCC, 1992d, p. 2)

Terms of Reference:

(i) to consider and review the universities' mechanisms for monitoring and promoting the academic standards which are necessary for achieving their stated aims and objectives;

(ii) to comment on the extent to which procedures in place in individual universities reflect best practice in maintaining quality and the extent to which they are carried out in practice;

(iii) to identify and commend to universities good practice in regard to the maintenance of academic standards at national level;

(iv) to consider and review the ways in which universities take account of the principles of the Treaty of Waitangi insofar as they relate to academic matters identified in (i) (ii) and (iii) above.

Focus of the work of the unit:

(i) mechanisms for quality assurance in the design, monitoring and evaluation of courses and programmes of study for degrees and other qualifications;

(ii) mechanisms for quality assurance in teaching, learning and assessment;

(iii) mechanisms for quality assurance in relation to the appointment and performance of academic staff;

(iv) mechanisms for taking account of the views in respect of academic matters of students, of external examiners, of professional bodies, and of employers;

(v) mechanisms for quality assurance in research, more especially, but not exclusively, in the context of its relationship with university teaching.

- that the panel of auditors include overseas representation to take account of New Zealand's size and the benefits of having international participation. The proposal is undecided, however, about whether auditors should be entirely drawn from academic circles, and suggests that universities give thought to the participation of lay membership; 
- that the function of the advisory board be to make recommendations to the NZVCC on the terms of reference and the operation of the unit. The proposal suggests that the board comprise both academic and non-academic membership, including Maori, student, employer and relevant professional representation;

- that audit panels comprise three members plus an audit secretary, and that visits to universities include examination of written documentation followed by a three day visit (the proposed methodology is similar to that of the AAU as outlined earlier);

- that universities be audited on a four year cycle to allow universities sufficient time to implement recommendations from previous audits.

\section{Conclusion: Preparing for Academic Audit}

Although the final go-ahead has yet to come from universities, and the terms of reference and scope of activities of the unit may undergo some modification, it now seems certain that 1993 will see the creation of a universities' academic audit unit. From the viewpoint of individual universities, this will mean close examination of their own procedures for assuring quality in their academic activities - indeed, some universities have already started such an examination. Inevitably a number of issues or problems will need to be tackled which will strain further, as Dearden (1992) points out, what is already an overstretched system. A number of points can be made on the problems or issues that the universities will face, but three change management principles are suggested here for consideration by universities as they begin to plug gaps in their systems and firm up existing practices:

1. Ensure that new systems and changes to old systems do not lead to an expansion of staff workloads.

2. Ensure that the benefits of the new systems are made fully transparent to all involved - staff, students and others who are likely to be affected by the changes.

3. Involve staff at all levels in the development of systems so that changes are related and accommodated to their needs, and thereby encourage acceptance and ownership.
The first of these is essential in the present climate where, in the view of the writer, increasing (and often unmanageable) workloads typify the work context of most academics. In reviewing and designing quality systems, universities should analyse the workload impact that such developments have on academics; any change that results in more work should be met by an equivalent saving elsewhere. For this reason it is important that different policies and practices be looked at together; for example, a system for handling student appeals on assessed work should be considered alongside systems for improving the reliability of marking in the first place - changes in one area may well result in savings in effort in the other. It should be added that Gordon (1992) sees the coordination of systems within universities as an issue emerging from academic audit in Britain.

At the same time, changes need to be seen by staff as beneficial to them - that more problems will be solved than created by new arrangements. Resistance to change is to be expected: quality audit, and the changes it brings, will be seen by many as a threat to existing values (e.g., academic freedom and autonomy) and practices (e.g., sticking with a preferred method of instruction). Staff are unlikely to change their attitudes or behaviour unless they can perceive academic value in the changes being introduced, or can see that such changes are consistent with their existing beliefs. Universities thus need to give careful consideration to both the changes they introduce and the means by which they implement and communicate such changes.

The third principle builds upon a point made by Williams (1992) in comparing institutions which have a strongly centralised (top-down) management system with those which encourage a more devolved structure. He sees the former as having good monitoring systems with well-defined procedures but encouraging a "compliance" attitude which may work against commitment to providing a quality environment; he sees the latter as encouraging participation and ownership in decisionmaking but providing less coordination for enabling an institution to monitor the effectiveness of its activities. If Williams is correct, universities need somehow to combine elements from both systems in order to develop effective QC and QA systems. The process may take time: universities should not rush the debate and negotiation that is necessary to enlist the support of staff at all levels. The important point is that quality is an everyday matter which depends on the full support of all participants in the process - in the classroom, in the preparation 
and marking of assessment tasks, in the procedures for designing and evaluating courses, and in the research programmes that staff and students undertake.

\section{References}

CUAP."Report on Universities Workshop on Quality Assurance, Wellington, 11-12 May 1992", in NZVCC, Quality Assurance in New Zealand Universities: Workshop File. Wellington: NZVCC, 1992

Dearden, C. Statement of Objectives/Statement of Service Performance. Wellington: Victoria University of Wellington, 1992.

Gordon, G. Quality Audit and Quality Assessment. Paper presented at the 14th Annual European Association for Institutional Research (EAIR) Forum, Brussels, 1992.

Hall, C. (a) Quality Assurance: Implications for NZ Universities from British Experience. Report on the NZVCC/UTDC seminar, Wellington: Victoria University of Wellington, University Teaching Development Centre, 1992.

Hall, C. (b) “Universities' Policies and Practices on Selected Quality Control/ Assurance Matters: Summary of Responses to a Request for Information", in NZVCC, Quality Assurance in New Zealand Universities: Workshop File. Wellington: NZVCC, 1992.

Hall, C. (c) "Workshop on Quality Assurance in New Zealand Universities: Summary of Papers and Discussion", in NZVCC, Quality Assurance in New Zealand Universities: Workshop File. Wellington: NZVCC, 1992. (It should be noted that two reports emanated from the second NZVCC workshop; the first (see CUAP above) focused on the arguments and recommendations for the creation of an academic audit unit, while the second provides details of the discussion and proceedings of the workshop.)

Hall, C. (d) "Questions about Quality: Focusing on Course Design and the Teaching-Learning Environment", in NZVCC, Quality Assurance in New Zealand Universities: Workshop File. Wellington: NZVCC, 1992.

Higher Education: A New Framework. London: HMSO, 1991. (This is also known as the "Higher Education White Paper, 1991".)

Jarrat, A. Report of the Steering Committee for Efficiency Studies in Universities. London: CVCP, 1985.

Jones, J. Quality and Academic Audit in the UK. Auckland: University of Auckland, HERO, 1992.

Kalkwijk, J. P. Th. Quality Assurance in Higher Education in the Netherlands. Paper presented at the International Conference on Quality Assurance in Higher Education, Hong Kong, 1991.
NZVCC. Assessment Procedures and Review Practices in New Zealand Universities. Wellington: NZVCC, 1991. (This paper also appears in NZVCC, Quality Assurance in New Zealand Universities: Workshop File. Wellington: NZVCC, 1992.)

NZVCC. (a) Quality Assurance in New Zealand Universities: Workshop File. Wellington: NZVCC, 1992.

NZVCC. (b) "Response to Academic Audit Unit Proposal", in NZVCC, Quality Assurance in New Zealand Universities: Workshop File. Wellington: NZVCC, 1992.

NZVCC. (c) Report on Seminar with Professor George Gordon of the CVCP (UK) Academic Audit Unit. Wellington: NZVCC, 1992.

NZVCC. (d) Proposal for a New Zealand Universities Academic Audit Unit. Wellington: NZVCC, 1992

Reynolds, P. A. Academic Standards in Universities. London: CVCP, 1986.

Vroeijenstijn, A. I. External Quality Assessment: Servant of Two Masters? Paper presented at the International Conference on Quality Assurance in Higher Education, Hong Kong, 1991.

Williams, P. R. The CVCP Academic Audit Unit. Paper presented at the International Conference on Quality Assurance in Higher Education, Hong Kong, 1991.

Williams, P. R. Academic Audit Unit: Annual Report of the Director 1990/91. London: CVCP, 1992.

\section{Acknowledgements}

I would like to thank the New Zealand Vice-Chancellors Committee for allowing me to cite freely from papers and documents contained in the NZVCC Workshop File (see NZVCC, 1992a above). All extracts are given in quotes except those taken from Hall (1992c); in the circumstances, I could see no point in trying to paraphrase my own writing. However, it should be acknowledged that the Hall (1992c) report draws upon the notes made of group discussions by facilitators during the May workshop; acknowledgments are therefore due to Gary Burns, Terry Crooks, Neil Fleming, Neil Haig, John Jones, and Rod McKay for the clarity of their notes.

\section{The author}

Cedric Hall is Director of the University Teaching Development Centre at Victoria University of Wellington. His research interests include course design, teaching methods, assessment and evaluation. 